\title{
Efficiency of Two Models for Prediction of Exchangeable Sodium Percentage from Sodium Adsorption Ratio on Saline and Non Saline Soil
}

\author{
Mohammed M. A. Elbashier, ${ }^{1,2,}$, Mohammed H. A. Ebrahim², Abdelrahaman A. Musa ${ }^{3}$, \\ Albashir A. S. Ali ${ }^{1,4}$, Moamer A. A. Mohammed ${ }^{3}$ \\ ${ }^{1}$ College of Water Conservancy and Hydropower Engineering, Hohai University, China \\ ${ }^{2}$ Department of Soil Conservation, Ministry of Agriculture, Khartoum State, Sudan \\ ${ }^{3}$ Department of Soil Science, College of Agricultural Studies, SUST, Sudan \\ ${ }^{4}$ Department of Soil Science, Agricultural Research Corporation, Khartoum, Sudan
}

Copyright $\mathrm{C} 2016$ by authors, all rights reserved. Authors agree that this article remains permanently open access under the terms of the Creative Commons Attribution License 4.0 International License

\begin{abstract}
The relationships between soil physical and chemical properties play a key role in facilitating the measurement of soil properties, particularly Exchangeable Sodium percentage (ESP) measurement, which is often using laborious and time-consuming laboratory tests. The aim of this study is to investigate the efficiency of the United States Salinity Laboratory (USSL) model and the ESP-SAR model for prediction of exchangeable Sodium percentage (ESP) from Sodium Adsorption Ratio (SAR) on saline and non-saline soil samples. For this purpose, 23 soil samples were collected from the field of experiment, Jabal Awliya, south of Khartoum state, Sudan. Exchangeable Sodium Percentage (ESP) was estimated as a function of soil SAR in order to compare the predicted results with measured ESP using laboratory tests. The results show that on saline soil samples, the Standard Error of Mean (SEM) of predicted ESP obtained by USSL model and ESP-SAR model was (1.084) and (1.463) respectively. On non- saline soil samples, the Standard Error of Mean (SEM) of predicted ESP acquired by USSL model was $(0.7034)$ and $(0.6070)$ for ESP-SAR model. The statistical results indicated that USSL model has a good prediction on saline soil samples compared with ESP-SAR model. On non-saline soil samples, USSL model showed less prediction performance than ESP-SAR model. It can be concluded that the United States Salinity Laboratory model can be recommended on saline soil samples and ESP-SAR model is more reliable on non-saline soil samples.
\end{abstract}

Keywords Exchangeable Sodium Percentage, Sodium Adsorption Ratio, Cation Exchange Capacity, United States Salinity Laboratory

\section{Introduction}

Agricultural practices in arid and semi-arid areas require continuous information on soil salinity and sodicity due to their negative impact on agricultural production. Graaff and Patterson, Robert and Ulery [1,2] stated that soil salinity refers to the total concentration of salts in the soil and soil sodicity represents the amount of exchangeable sodium relative to other exchangeable cations. Keshavarzi [3] reported that soluble salts affect the productivity of soils in two principal ways: changing the osmotic potential of soil solution and increasing the content of exchangeable sodium. Seilsepour et al., [4] explained that soil salinity and sodicity are recognized by soil Sodium Adsorption Ratio (SAR) and Exchangeable Sodium Percentage (ESP) and these are defined as Eq. (1) and Eq. (2):

$$
\text { SAR }=\frac{\mathrm{Na}^{+}}{\sqrt{\left(\mathrm{Ca}^{++}+\mathrm{Mg}^{++}\right) / 2}}
$$

Where:

$\mathrm{SAR}=$ Sodium Adsorption Ratio.

$\mathrm{Na}^{+}, \mathrm{Mg}^{++}$and $\mathrm{Ca}^{++}=$Soluble cations in soil solution $(\mathrm{meq} / \mathrm{L})$

$$
\left(\text { Exchangeable } \mathrm{Na}^{+} / \mathrm{CEC}\right) \times 100
$$

Where:

$\mathrm{ESP}=$ Exchangeable Sodium Percent, $\%$.

$\mathrm{Na}+=$ Measured exchangeable $\mathrm{Na}^{+}$, meq/100g.

$\mathrm{CEC}=$ Cation Exchange Capacity, meq/100g.

Musslewhite and Song [5] noticed that measurement of ESP is using laborious and time-consuming laboratory tests through determination of Cation Exchange Capacity (CEC) and exchangeable $\mathrm{Na}^{+}$, therefore the prediction of ESP from SAR is useful due to their existed relation. Previous studies report a relationship between ESP and SAR, Harront et al., 
and Richards [6, 7], so SAR became an important tool to predict the ESP in salts affected soils, Robbins [8]. A pedo transfer function is derived by Rashidi and Seilsepour [9] for calculating the amount of ESP given the soil SAR, as ESP = $1.95+1.03 \mathrm{SAR}$. The model resulting from the combination of soil ESP and SAR has a remarkable advantage in term of providing an easy and economical methodology for estimating the soil ESP.

This study aims to investigate the efficiency of two models for prediction of Exchangeable Sodium Percentage (ESP) from Sodium Adsorption Ratio (SAR), on saline and non-saline soil samples.

\section{Material and Methods}

\subsection{Experimental Procedure}

Twenty-three soil samples (Eighteen soil samples exemplified saline soil samples and five soil samples represented non-saline soil) were taken randomly from the field of experiment, Jabal Awliya, south of Khartoum state, Sudan. Some physical and chemical properties of soil under investigation are shown in Table 1. For instance, Sand, silt and clay content ( $\%$ by weight) and $\mathrm{pH}, \mathrm{EC}, \mathrm{SAR}$ and ESP were measured using laboratory tests as described by Richards [7]. In this paper, two well-known models, which are United States Salinity Laboratory (USSL) model, described by Richards [7] and the ESP-SAR model described by Rashidi and Seilsepour [9], were considered to predict ESP from SAR. The results of those models were directly compared with the laboratory experimental ones using some statistical measurements.

Table 1. Some chemical and physical analysis for soil samples

\begin{tabular}{|c|c|c|}
\hline Parameter & Saline soil & Non-saline soil \\
\hline $\mathrm{ECe}(\mathrm{dS} / \mathrm{m})$ & 4.4 to 12.3 & 0.95 to \\
\hline $\mathrm{pH}$ & 7.7 to 8.6 & 7.7 to 8.6 \\
\hline Texture & Sandy Clay Loam & Sandy Clay Loam \\
\hline
\end{tabular}

ECe: Electrical Conductivity of soil saturated extract.

\subsection{Statistical Analysis}

A paired samples t-test analyses; the mean difference confidence interval, the standard deviation of difference, standard Error of Mean (SEM) and p-value were used to compare the soil ESP values predicted using USSL model and ESP-SAR model with the soil ESP values measured by laboratory tests.

\section{Results}

The soil SAR values used for predicting the soil ESP by USSL model, ESP-SAR model and the measured ESP by laboratory tests on saline and non-saline soil samples are shown in table 2 and table 3 respectively. Average difference, standard deviation of difference, standard error of mean (SEM), 95\% confidence intervals for the difference in means and the p-value of the two models on saline soil samples and non-saline soil samples are calculated to evaluate the efficiency of the two models compared to the measured laboratory test values as a reference. The results of these statistical analyses using paired samples t-test are shown in Table 4 and Table 5 respectively.

Table 2. Chemical properties of soil used for predicting soil ESP by USSL model and ESP-SAR model on saline soil samples:

\begin{tabular}{ccccc}
\hline $\begin{array}{c}\text { Sample } \\
\text { No. }\end{array}$ & SAR & $\begin{array}{c}\text { Laboratory } \\
\text { tested ESP }\end{array}$ & $\begin{array}{c}\text { Predicted } \\
\text { ESP } \\
\text { USSL } \\
\text { model }\end{array}$ & $\begin{array}{c}\text { Predicted } \\
\text { ESP } \\
\text { ESP-SAR } \\
\text { model }\end{array}$ \\
1 & 47 & 35 & 40.5 & 50.4 \\
2 & 45 & 40 & 39.4 & 48.3 \\
3 & 18 & 19 & 20.2 & 20.5 \\
4 & 27 & 23 & 28.3 & 29.8 \\
5 & 16 & 13 & 18.3 & 18.4 \\
6 & 17 & 22 & 19.2 & 19.5 \\
7 & 15 & 14 & 17.3 & 17.4 \\
8 & 36 & 25 & 34.1 & 39.0 \\
9 & 12 & 19 & 14.1 & 14.3 \\
10 & 50 & 45 & 42.0 & 53.5 \\
11 & 28 & 20 & 28.6 & 30.8 \\
12 & 21 & 17 & 22.9 & 23.6 \\
13 & 20 & 19 & 22.0 & 22.6 \\
14 & 40 & 39 & 36.6 & 43.2 \\
15 & 46 & 31 & 40.0 & 49.3 \\
16 & 43 & 38 & 38.3 & 46.2 \\
17 & 32 & 33 & 31.5 & 34.9 \\
18 & 22 & 27 & 23.8 & 24.6 \\
\hline
\end{tabular}

Table 3. Chemical properties of soil used for predicting soil ESP by USSL model and ESP-SAR model on non- saline soil samples:

\begin{tabular}{ccccc}
\hline $\begin{array}{c}\text { Sample } \\
\text { No. }\end{array}$ & SAR & $\begin{array}{c}\text { Laboratory } \\
\text { tested ESP }\end{array}$ & $\begin{array}{c}\text { Predicted ESP } \\
\text { USSL model }\end{array}$ & $\begin{array}{c}\text { Predicted ESP } \\
\text { ESP-SAR } \\
\text { model }\end{array}$ \\
1 & 1 & 5 & 0.21 & 2.98 \\
2 & 1 & 6 & 0.21 & 2.98 \\
3 & 2 & 4 & 1.65 & 4.01 \\
4 & 1 & 5 & 0.21 & 2.98 \\
5 & 2 & 4 & 1.65 & 4.01 \\
\hline
\end{tabular}


Table 4. Paired samples t-test analyses on comparing soil ESP determination methods on saline soil samples.

\begin{tabular}{cccccc}
\hline Determination methods & $\begin{array}{c}\text { Average } \\
\text { Difference } \\
(\%)\end{array}$ & $\begin{array}{c}\text { Standard deviation of } \\
\text { difference (\%) }\end{array}$ & $\begin{array}{c}\text { Standard Error of } \\
\text { Mean (SEM) }\end{array}$ & p-value & $\begin{array}{c}95 \% \text { confidence intervals } \\
\text { for the difference in means }\end{array}$ \\
$\begin{array}{c}\text { USSL model \& laboratory test } \\
\begin{array}{c}\text { ESP-SAR model \& laboratory } \\
\text { test }\end{array}\end{array}$ & 5.117 & 4.597 & 1.084 & 0.0674 & -0.1694 to 4.403 \\
\hline
\end{tabular}

Table 5. Paired samples t-test analyses on comparing soil ESP determination methods on non-saline soil samples.

\begin{tabular}{cccccc}
\hline Determination methods & $\begin{array}{c}\text { Average } \\
\text { Difference } \\
(\%)\end{array}$ & $\begin{array}{c}\text { Standard deviation of } \\
\text { difference (\%) }\end{array}$ & $\begin{array}{c}\text { Standard Error of } \\
\text { Mean (SEM) }\end{array}$ & p-value & $\begin{array}{c}95 \% \text { confidence intervals } \\
\text { for the difference in means }\end{array}$ \\
$\begin{array}{c}\text { USSL model \& laboratory test } \\
\begin{array}{c}\text { ESP-SAR model \& laboratory } \\
\text { test }\end{array}\end{array}$ & -4.014 & 1.573 & 0.7034 & 0.0047 & -5.967 to -2.061 \\
\hline
\end{tabular}

\section{Discussion}

On saline soil samples:

A paired samples t-test analyses and the mean difference confidence interval approach were used to compare the soil ESP values predicted using the USSL model and ESP-SAR model with the soil ESP values measured by laboratory tests are shown in Table 4. For saline soil samples, it clear from Figure 1 that the USSL model demonstrated a high degree of agreement with the experimentally measured values compared to the ESP-SAR model. The mean of soil ESP difference between the two models and measured ESP was 2.117 for the USSL model and 5.961 for the ESP-SAR model. The $95 \%$ confidence interval was -0.1694 to 4.403 for the USSL model and 2.875 to 9.047 for the ESP-SAR model. A p-value of 0.0674 is obtained using USSL model while 0.0008 was obtained using ESP-SAR model. The standard deviation of the soil ESP differences for the USSL model was 4.597 and 6.205 for the ESP-SAR model. The Standard Error of Mean (SEM) of predicted ESP acquired by the USSL model related to the measured ESP was 1.084 and 1.463 for the ESP-SAR model. The paired samples t-test results demonstrated that the soil ESP values predicted with USSL model were not significantly different with the soil ESP measured by laboratory tests meanwhile, the soil ESP values predicted by the ESP-SAR model were significantly different with the ESP values measured by laboratory tests (Table 4). This also indicates a high agreement with the results obtained by Richards [6], Rashidi and Seilsepour [8].

On non-saline soil samples:

The mean of soil ESP difference between the two models and measured ESP was -4.014 for the USSL model and -1.408 for the ESP-SAR model. The $95 \%$ confidence interval was -5.967 to -2.061 for the USSL model and -3.093 to 0.2773 for the ESP-SAR model. A p-value was 0.0047, 0.0812 respectively for the USSL model and ESP-SAR model. The standard deviation of the soil ESP differences for the USSL model was 1.573 and the ESP-SAR model was 1.357. For non-saline soil samples, it clear from Figure 2 that the ESP-SAR model showed a high degree of agreement with the experimentally measured values compared to the USSL model. The Standard Error of Mean (SEM) of predicted ESP acquired by the USSL model related to the measured ESP was 0.7034 and 0.6070 for the ESP-SAR model. The results of paired samples t-test showed that the soil ESP values predicted using USSL model were significantly different with the soil ESP measured by laboratory tests and the soil ESP values predicted using ESP-SAR model were no significantly different with ESP values measured by laboratory tests (Table 5), this agrees with Rashidi and Seilsepour [8]. 


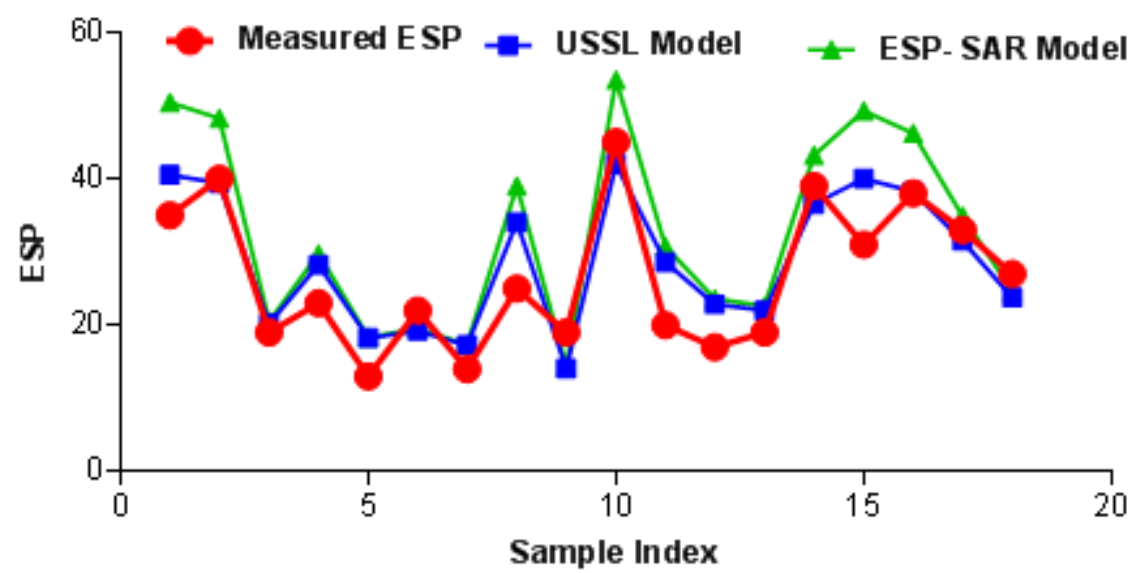

Figure 1. Measured ESP and predicted ESP using the USSL model and the ESP-SAR model on saline soil samples

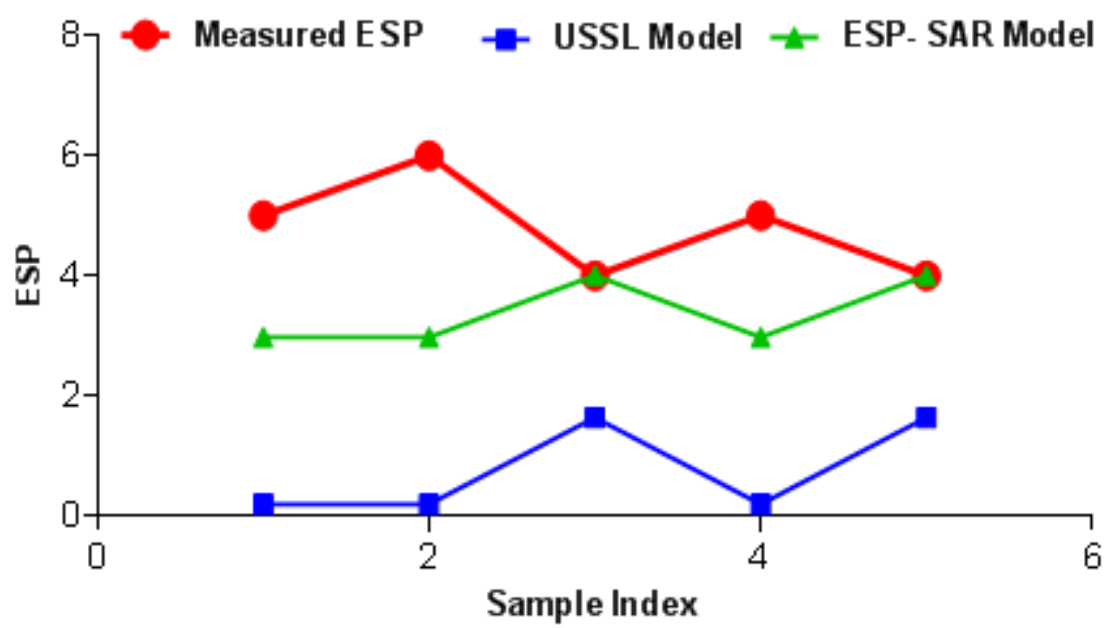

Figure 2. Measured ESP and predicted ESP using the USSL model and the ESP-SAR model on non-saline soil samples

\section{Conclusions}

In this paper, USSL model and ESP-SAR model were used to predict soil ESP from soil SAR on saline and non-saline soil samples. The paired samples t-test results on saline soil samples indicated that there was no difference between the ESP values predicted by the USSL model and the measured values by laboratory tests ( $p>0.05$, SEM was 1.084), while the soil ESP values predicted by the ESP-SAR model showed a significant difference $(p>0.0008$, SEM was $1.463)$ with the values that measured by laboratory tests. The statistical results on non-saline soil samples showed that there was no difference between the ESP values predicted by the ESP-SAR model and the measured values by laboratory tests ( $p>0.05$, SEM was 0.6070), and the soil ESP values predicted by the USSL model demonstrated a significant difference ( $p>0.0047$, SEM was 0.7034$)$ with the ESP values that acquired by laboratory tests. The results of this work would aid in determining the appropriate model for prediction of ESP from SAR on saline and non-saline soils. The United States Salinity Laboratory model can be recommended for prediction of soil ESP from soil SAR on saline soil samples and the ESP-SAR model is more suitable for non-saline soil samples.

\section{Acknowledgements}

This study was carried out at the Laboratory of Agricultural Analysis, Department of Soil and Water Analysis, Ministry of Agriculture, Khartoum State- Sudan. The authors would like to greatly express their deepest and warm gratefulness to the staff at Laboratory of Agricultural Analysis for their remarkable support.

\section{REFERENCES}

[1] R. Graaff, R. A. Patterson. Explaining the Mysteries of Salinity, Sodicity, SAR and ESP in On-site Practice in Proceedings of On-site ' 01 Conference: Advancing On-site Wastewater Systems, Lanfax Laboratories, Armidale. pp: 361 $-368,2001$.

[2] F. Robert and A. Ulery. An Introduction to Soil Salinity and Sodium Issues in New Mexico, las cruces, circular 656. PP: 16,2011 .

[3] A. Keshavarzi and F. Sarmadian. Mapping of Spatial Distribution of Soil Salinity and Alkalinity in a Semi-arid Region, Annals of Warsaw University of Life Sciences, Land Reclamation. 44 (1) 3-14, 2012. 
[4] M. Seilsepour, M. Rashidi, and B. G. Khabbaz. Prediction of Soil Exchangeable Sodium Percentage Based on Soil Sodium Adsorption Ratio, American-Eurasian Journal of Agriculture \& Environment Science, 5 (1): 01-04, 2009.

[5] B. Musslewhite and J. Song. Salinity and Sodicity Interactions of Weathered Mine Soils in North Western New Mexico and North Eastern Arizona, Topical and Final, Report Task 47 Jointly Sponsored Research Project, pp: 7-8, 2006.

[6] W. R. A. Harront, G. R. Webster, and R. R. Carins. Relationship between Exchangeable Sodium Percentage and Sodium Adsorption Ratio in a Soloonetzic Soil Association, Canadian Journal of Soil Science, (63): 461-467, 1983.
[7] L.A. Richards. Diagnosis and Improvement of Saline and Alkali Soils, Determination of the properties of saline and alkali soils United States Department of Agriculture, Washington, DC. pp: 26, 72, 1954.

[8] C. W. Robbins. Sodium Adsorption Ratio-Exchangeable Sodium Percentage Relationships in a High Potassium Saline-Sodic Soil. Irrigation Science (5): 173-179, 2004.

[9] M. Rashidi and Seilsepour, M. Sodium Adsorption Ratio Pedo transfer Function for Calcareous Soils of Varamin Region, International Journal of Agriculture \& Biology. 10 (6): 715718, 2008. 